\title{
Analysis of Hospital Production: An Output Index Approach
}

\author{
Martin S. Gaynor \\ Carnegie Mellon University \\ University of Bristol \\ NBER
}

\author{
Samuel A. Kleiner \\ Cornell University \\ NBER
}

March 30, 2012

\author{
William B. Vogt \\ University of Georgia
}




\section{Introduction}

The estimation of multiproduct cost functions is one of the most important tools for applied production analysis. Flexible form cost functions have been used to inform aspects of antitrust and regulatory policy in a wide variety of industries including banking (Pulley \& Braunstein, 1992), public utilities (Garcia \& Thomas, 2001; Kim, 1987), telecommunications (Röller, 1990), railways (Caves, Christensen \& Tretheway, 1980), agriculture (Moschini, 1988), hospitals (Cowing \& Holtmann, 1983; Vita, 1990) and natural resource industries (Toft \& Bjørndal, 1997). While the use of these techniques is widespread across both diversified and specialized firms, econometric and data limitations necessitate the simplification of the output space, thereby imposing restrictions on the production properties that can be analyzed. Such restrictions are particularly pertinent for industries producing highly heterogeneous goods where the nature of output is differentiated not only by the number of outputs produced by a firm, but also along dimensions within each measure unit of output (e.g., law firms, car repair, home construction).

Hospitals are a noteworthy example of such an industry, as they produce hundreds or even thousands of outputs. For example, there are over 500 Diagnosis Related Groups (DRGs), and each output differs by individual patient as to the degree of disease severity and complexity required for treatment. As Breyer (1987) notes, when analyzing hospital production, the curse of dimensionality precludes estimation of a production function which adequately accounts for case heterogeneity while also maintaining a sufficiently flexible functional form to allow for theoretically sound estimates of scale and scope economies. The difficulty in analyzing the hospital production is evident in that despite a 
large literature estimating hospital costs, few firm conclusions can be drawn from it (Gaynor \& Vogt, 2000).

Two related problems have prevented a firm consensus from emerging on the extent and size of scale economies and scope economies in the hospital industry. First, previous studies have been limited in their ability to adequately control for the types of patients and severity of illnesses treated at a hospital. To the extent that large hospitals treat more complex and costly cases, measures of scale economies will be biased downward. Second, previous studies capture output via very aggregate measures. Because larger hospitals usually have a broader range of services available and provide more specialized treatments which are often more costly, the simplification of the hospital output space may result in an incorrectly measured scope of output. To the extent that scope and scale covary, this simplification of the output space may affect measurement of true scale and scope economies.

In this study, we estimate a new model of hospital costs which improves on previous studies in two fundamental ways. First, the availability of detailed micro data allows us to flexibly model output using an output index which is constructed to accurately reflect the highly differentiated nature of hospital care by employing both patient and diagnosis characteristics in its construction. Second, we develop a method that better accounts for the hundreds of outputs produced by a hospital by building into our model a proxy for output diversity within the aggregation categories used in the estimation of our cost function. Using this output index, we estimate a translog cost function with a dataset of 321 California hospitals for the year 2003. We find evidence of scope economies across specialties within primary care, and evidence of scope 
diseconomies across specialties within secondary and tertiary care. Our estimates also suggest that scale economies are exhausted within a range that is higher than would be implied by methods that are used in previous studies of hospital costs.

This paper proceeds as follows. Section 2 provides background on previous estimation of hospital production. Section 3 discusses production theoretic issues related to the estimation of a multiproduct cost function. Section 4 describes our data, while Section 5 details the methods used for the estimation of the index. Section 6 presents the results of our estimation, while Section 7 demonstrates the extent of scope and scale economics implied by our specification, while also comparing these estimates to those found using methods embodying the assumptions employed in previous studies. Section 8 concludes.

\section{Previous Literature}

Studies of industry costs form one of the cornerstones of empirical microeconomics. Since the seminal work of Baumol, Panzar and Willig (1982), economists have become increasingly interested analyzing the production properties of multiproduct firms. A large number of empirical studies have analyzed the production properties of goods and services in industries as varied as higher education (Cohn, Rhine \& Santos, 1989), crime prevention (Gyimah-Brempon, 1987), electric utilities (Nelson, 1985) and airlines (Caves, Christensen \& Tretheway, 1984), and have provided considerable evidence of the economic and policy significance of the presence scale and scope economies. 
Due to the unique characteristics of the hospital industry, a large number of studies in this literature focus on hospitals. While early literature on hospital cost estimation was based upon ad hoc regression specifications, more recent studies analyze production using neoclassical specifications. These studies have produced mixed results and are largely inconclusive as to the presence of hospital scale economies, with most finding limited evidence of scale economies beyond around 200 beds (Dranove, 1998; Gaynor \& Vogt, 2000). For example, Vita (1990), Keeler and Ying (1996), Conrad and Strauss (1983), and Granneman, Brown and Pauly (1986) all find no scale economies for inpatient care and weak scale diseconomies for all levels of output. Alternatively, Fournier and Mitchell (1992), Carey (1997), Cowing and Holtman (1983), Dor and Farley (1996), Dranove (1998), Gaynor and Anderson (1995), and Preyra and Pink (2006) find evidence of scale economies. ${ }^{1}$ The evidence is also inconclusive among the subset of these studies to examine the presence of scope economies. Cowing and Holtman (1983) find limited evidence of scope economies, while Vita (1990) finds no scope economies using a similar specification. Fournier and Mitchell (1992) find evidence of significant scope economies, while Preyra and Pink (2006) also find evidence supporting economies of scope, particularly between primary and ambulatory care.

Two issues have likely prevented a consensus as to the presence of scale and scope economies in this industry. First, hospital case mix has not been well controlled for in studies to date. To the extent that large hospitals treat more complex and costly cases, measures of scale economies may thus exhibit a downward bias. Second, hospitals produce many outputs which previous studies capture in especially aggregated measures

\footnotetext{
${ }^{1}$ It should be noted that the imprecision of Fournier and Mitchell's (1992) estimates cannot reject findings of constant returns to scale. Vita's (1990) recalculation of Cowing and Holtman's (1983) measures finds no evidence of scale economies.
} 
with little consideration paid to whether these aggregation units fit within the theoretical conditions required for such aggregation. Furthermore, within these aggregated units, the structure of the industry is such that larger hospitals typically offer a broader range of services and provide more specialized and costly treatments. To the extent that the measurement of output within an aggregated category fails to account for the scope of output which also varies positively with the scale of output, and because the marginally added output is likely more costly than average, this effect may work to depress measurements of true scale economies for large hospitals.

\section{Methods}

The following section discusses our method of estimating hospital costs, which improves on previous studies in its grouping and definition of hospital output. This method measures hospital output in a way that differentiates each production unit using patient diagnosis and demographic characteristics. Furthermore, we structure the output definition within our estimated function to more thoroughly account for the numerous types of specialties treated within a hospital. The method proceeds by first modifying the neoclassical cost function framework in a manner better suited to multi-output firms, thus allowing for estimation of specialty specific scope economies within an output category. We then detail our method of quantifying output in a manner which better reflects diagnostic and patient heterogeneity through our use of hospital charges as a proxy for the amount of hospital care provided.

\subsection{Model of Production}


We model the output space of hospital production as a consisting of a total of $K$ aggregate outputs. As noted in Hall (1973) and Preyra and Pink (2006), appropriate aggregation of output necessitates that the ratios of the marginal costs of any two aggregated outputs be independent of input prices. This implies that within an aggregated output, a firm can choose its allocation of outputs independent of its allocation of inputs. For hospital output, this implies that within each output aggregation category, each output should be similar with respect to the inputs required for the production of those outputs. Given these conditions, we adopt the approach taken by Preyra and Pink (2006) which classifies care according to the resource intensity of each output. For example, because tertiary care requires extensive diagnostic equipment and technical expertise and is often provided primarily at a teaching or university-affiliated hospital, this type of care would be grouped into a separate category than primary care which requires non-specialized labor and low-cost capital assets. Assuming the satisfaction of these aggregation conditions, following McFadden (1978), a hospital's production technology for $K$ outputs can be represented by the cost function:

$$
\text { Cost }=C\left(Q_{1}, Q_{2}, \ldots, Q_{K}, \boldsymbol{w}\right)
$$

where each $Q$ denotes an aggregated output type, and $\mathbf{w}$ a vector of input prices.

Hospitals also vary with respect to their degree of specialization within each type of output produced. For example, faced with the possibility of specializing in $N$ different areas, hospitals often focus on providing a limited amount of specialized care, such as tertiary cardiac care, while providing secondary and primary care for a more diverse set of conditions. A more complete model of hospital production should thus account not only for the amount of each type of output produced but also the level of within-output 
specialization. For example, a hospital providing digestive system care may purchase laparoscopic equipment for the purposes of performing an appendectomy. This equipment may have multiple uses that extend to other specialties such as gynecology (e.g. laparoscopic hysterectomy) or nephrology (e.g. laparoscopic nephrectomy), thus implying the existence of economies of scope (decreasing marginal costs to diversity) within each output type. Conventional means of aggregating output implies no economies or diseconomies of scope across specialties within an output type. Within each output type, we therefore model the quantity of output among the $N$ medical specialties treated at a hospital (e.g., cardiac, neurology, etc.) in a form which allows for the existence of within output-type economies of scope, in order to determine whether such economies of scope are present for hospital care. More specifically, within output type $k$, we allow for the existence of scope economies within output types according to the functional form:

$$
Q_{k}=\left(Q_{k 1}^{\rho_{k}}+\cdots+Q_{k N}^{\rho_{k}}\right)^{\frac{1}{\rho_{k}}}
$$

where the extent of scope economies is determined by the value of the parameter $\rho_{k}$. Based on this assumption, (1) can be rewritten as:

Cost $=C\left[\left(Q_{11}^{\rho_{1}}+\cdots+Q_{1 N}^{\rho_{1}}\right)^{\frac{1}{\rho_{1}}},\left(Q_{21}^{\rho_{2}}+\cdots+Q_{2 N}^{\rho_{2}}\right)^{\frac{1}{\rho_{2}}}, \ldots,\left(Q_{K 1}^{\rho_{K}}+\cdots+Q_{K N}^{\rho_{K}}\right)^{\frac{1}{\rho_{K}}}, \boldsymbol{w}\right]$

In equation (3), while the cost function varies with the level of output type $Q_{k}$ produced, the cost of each unit of output also varies by the diversity of specialties offered at a hospital within output type $Q_{k}$. 
To illustrate this, suppose that a hospital produces primary and secondary care, each denoted by subscripts $p$ and $s$, and specializes in only cardiac and obstetrics within each output type, each denoted by subscripts $c$ and $o$. The cost to a hospital using

equation (3) can be written as Cost $=C\left[\left(Q_{p c}^{1 / \rho_{p}}+Q_{p o}^{1 / \rho_{p}}\right)^{1 / \rho_{p}},\left(Q_{s c}^{1 / \rho_{s}}+Q_{s o}^{1 / \rho_{s}}\right)^{1 / \rho_{s}}, \boldsymbol{w}\right]$ where cost varies not only by the total units of primary and secondary care produced, but also the degree of scope economies between obstetric care and cardiac care. Within this framework, given that $\mathrm{C}$ is an increasing function in all of its arguments, a value of $\rho_{k}>1$ indicates the presence of economies of scope, while a value of $\rho_{k}<1$ corresponds to diseconomies of scope for producing multiple specialties within an output type.

\subsection{Output Measurement}

Within our framework, we require a measurement of hospital output which can be quantified in a manner consistent with the aggregation conditions detailed above, while also allowing for segmentation by specialty within these aggregated categories. In addition, such a measure of output should adequately control for case complexity and patient characteristics within a resource category, in order to account for the differing treatment protocols of treating patients of different ages and with greater numbers of complicating conditions. To accomplish this, we adopt an approach to output measurement using gross hospital charges in a way that accounts for consumer and diagnostic heterogeneity. Specifically, our approach uses list prices (charges) to proxy for quantity, where total hospital spending for each patient acts a weighted quantity index. Because list prices are constructed from a uniform charge list which is identical for each 
hospital patient, for each item billed to a patient, charges can be interpreted as a quantity index weighted by a price for that item.

Our approach to the construction of the output index incorporates institutional evidence regarding the structure of charge lists and commonly used reimbursement practices. The assumption of a proportional relationship between the cost of care and gross hospital charges is an important determining factor in the calculation of outlier payments used by Medicare (Wynn, 2003). While disparities between these charges and costs have been growing over time, Dobson et al. (2005) note that it is common practice for hospitals to examine the relationship between charges and costs when pricing new services, and report that changes in the cost of specific services and procedures are an important factor influencing the decision of hospital administrations to modify their charge master. Their report, however, notes that the assumption of a constant mark-up across all services (as is the case for Medicare outlier reimbursement) does not accurately reflect charge setting. In addition, Dobson et al. (2005) document variation in hospital charges depending on hospital-specific factors such as market power, ability to estimate costs, and overall financial position.

Because of this variation in charge setting procedures both across hospitals and within hospitals but across diagnoses, our method of quantifying output using hospital charges accounts for differences in hospital-specific attributes and mark-ups by controlling for differences in mark-ups for individual hospitals, service intensity, and medical specialty. We model charges for individual $i$ receiving treatment at hospital $j$ for output type $k$ as being proportional to the quantity of patient care, $q_{i k}$ where $k$ denotes the output type consumed by individual $i$. For any given hospital, the quantity of $Q_{k}$ 
produced is assumed to consist of the summation over the total number of individuals receiving care at hospital $k$, such that $Q_{j k}=\sum_{i \rightarrow j} q_{i k}$ where $i \rightarrow j$ denotes person $i$ receiving care at hospital $j$. Mark-ups for each type of care are assumed to differ within an individual hospital across both output types as well as specialty types. Employing this structure, charges for patient $i$ consuming $q_{i k}$ units of output $k$ at hospital $j$ can be written as:

$$
H_{i j k n}=\gamma_{j k} \frac{\partial C_{j}}{\partial Q_{k}} \times \frac{\partial Q_{k}}{\partial Q_{k n}} \times q_{i k}
$$

where $\gamma_{j k}$ is the markup over marginal cost for hospital $j$, output type $k, \frac{\partial C_{j}}{\partial Q_{k}}$ is the marginal cost for output type $k$ at hospital $j$, and $\frac{\partial Q_{k}}{\partial Q_{k n}}$ is a specialty specific term which denotes the change in the amount of output $k$ produced by employing an additional unit of specialty $n$, a term which varies by output-specialty type.

Though our output measure offers a more exhaustive set of controls for patient and diagnosis heterogeneity, we note two limitations of this output measure. First, as in most studies of hospital costs, our output measure is ultimately based on the physical quantity of hospital services provided to a patient. As noted by Butler (1995), whether the output of a hospital should be defined as improvement in the health status of the patient, rather than actual provision of the medical treatment itself is debatable. Second, as Romley and Goldman (2011) note, unobserved or incorrectly measured variations in quality can affect estimates of the properties of hospital production. Though scale economies are not specifically measured in their study, their findings of a positive correlation between productivity and quality imply that failure to account for quality may potentially understate quality adjusted productivity, leading to an underestimate of scale 
economies. Thus, while our method does offer a more thorough treatment of case complexity and patient characteristics when modeling hospital output than do past studies of hospital costs, our estimates of scale economies will be conservative - scale economies will be understated if there is a bias due to omitted quality.

\section{Data}

We use data from California's Office of Statewide Health Planning and Development (OSHPD) which maintains a variety of datasets on various aspects of health care in the state. Below we briefly describe each of the particular datasets that we draw upon and the criteria for selecting subsets of the data.

\subsection{Discharge Data}

All nonfederal California hospitals are required to submit specific data on every patient discharged from their facility including information on patient demographics, diagnostic and treatment information, payment source, and total charges. These data are reported for the full calendar year and include detailed patient information including age, race, sex, and county of residence as well as diagnosis characteristics. A number of patient demographic characteristics are masked in the data for characteristics which OSHPD determines could, due to small cell sizes, reveal identifying information. Other sensitive items such as age are entered categorically. These data also contain charges based on hospital's full established rates. As we detail in section 3.2, though these charges are a poor proxy for actual price paid, they are calculated as the product of the 
services provided multiplied by a price contained in a uniform charge master list for each hospital and are thus related to the amount of care consumed by a patient.

\subsection{Financial Data}

The submission of an annual financial report including a detailed income statement, balance sheet, statements of revenue and expense, and supporting schedules, as well as a quarterly hospital financial report is required of all California hospitals. These financial reports are based on a uniform accounting and reporting system developed and maintained by the OSHPD. The annual financial data correspond to hospital fiscal years which are not necessarily synchronized with calendar years while the quarterly data are synchronized with both calendar years and each other. The annual data contain variables useful to the construction of input prices such as hourly wages, hours, benefits, and data on the hospital physical plant. These items are likely not to be sensitive to synchronization and are thus used in the construction of input prices. There is also information on ownership and teaching status in these data. The quarterly data contain items such as outpatient visits and total operating expenses which require synchronization with the discharge data in order to accurately estimate the relationship between hospital output and cost. For these items, we sum the quarterly data up to annual levels and use this in the construction of our total cost and outpatient visit variables.

\subsection{Selections and Variable Construction}

For 2003, there are over 3.9 million discharges in the data. Because we require a value of hospital charges in the construction of our output index, we eliminate Kaiser 
hospitals which are members of a vertically integrated organization and thus do not report charges. We also eliminate Shriner's hospitals which do not charge their patients.

Because our universe is short-term general hospitals, we eliminate children's hospitals, and hospitals specializing in psychiatric, chemical dependency, or long-term care. After all exclusions, we are left with 3,238,799 discharges from 321 hospitals. Demographic and severity characteristics of the patients in our sample are included in the first column of Table 1.

For the construction of both our input prices and capital variables, we employ the financial data which separate out the average hourly wage at each hospital by type of labor. To calculate input prices for each type of labor we first multiply the hourly wage by the total number of hours (both productive and non productive) worked for each labor type. Because benefits also account for a substantial portion of compensation, we allocate a portion of total benefits to each labor type based on the total number of hours worked. Our share data is calculated using this amount of total compensation for each type of labor divided by the total cost (see below). ${ }^{2}$ Using this measure we divide by the total number of hours worked to get the input price by labor type at each hospital.

Construction of capital prices and quantities in cost function estimation is notoriously difficult (Folland, Goodman \& Stano, 2004). We construct an economic measure based on construction costs for hospitals in California in 2003. We start with the total square feet present at a hospital, available in the OSHPD financial data. Meade and Kulick (2007) conclude that the cost for a fully furnished hospital building in 2006 is approximately $\$ 1,000$ per square foot. Because hospital costs have increased at a rate

\footnotetext{
${ }^{2}$ For hospitals reporting data for only part of a year, we scale the share number up by [12/(\# of months reporting)] while leaving the hourly measure unchanged.
} 
larger than that of inflation, we deflate this to a 2003 cost using a hospital cost deflator specified in a report commissioned by the California Hospital Association. ${ }^{3}$ Using these two measures, we now have an approximation of the total dollar amount of capital possessed by each hospital. To construct the price for this capital, we employ the average interest rate for corporate industrial bonds and municipal bonds as reported for 2003 from the Mergent Bond Record (2007). Not-for-profit hospitals are assigned the municipal bond interest rate due to their tax-exempt status, while for-profits are assigned the industrial rate. We then add to this measure the cost of depreciation based on our calculated dollar value of hospital capital. We assume a 40 -year useful life as reported in a recent report by California's Office of Statewide Health Planning \& Development $(2005){ }^{4}$

For our measure of cost, we use the sum of total operating expenses as reported by the quarterly data. Because a portion of these expenses contain capital-related items, we subtract out depreciation, rental, and interest expense. Using this measure, we then add back the capital expense as computed above.

Our classification of inpatient discharges into our three output categories (primary care, secondary care, tertiary care) is done using a ranking system developed by the Hay Group (2001) in Canada to assign diagnoses to the resource requirements for each type of care. This methodology was developed specifically to identify factors that could proxy for the complexity of each diagnosis. Our ranking methodology closely follows this method, using the following criteria in our ranking scheme:

\footnotetext{
${ }^{3}$ See Morris, Peter (2006). "Construction Cost Escalation in California Healthcare Projects - January 2006," Davis Langdon Report. Available at: http://207.104.162.65/WhatsNew/Langdon $\% 20$ Construction $\% 20 \mathrm{Cost} \% 20$ Escalation $\% 20 \mathrm{in} \% 20 \mathrm{CA} \% 20 \mathrm{Jan}$ uary $\% 202006 \% 20 \mathrm{no} \% 20$ cover\%20letter.pdf [Accessed March 27, 2012]

${ }^{4}$ See page 18 of this report.
} 
1) Rank DRGs by the number of hospitals having at least 1 case with this diagnosis. This is a measure of the current distribution of the patient type across hospitals. Fewer hospitals indicate a higher rank, since diagnoses treated at few hospitals likely require specialized resources.

2) Rank DRGs by the percentage of urban hospital service that is provided to residents in non-urban areas. This is a measure of the disproportionate inflow of patients into an urban hospital to receive specialized services not available in their own communities. Higher percentages indicate a higher rank. ${ }^{5}$

3) Rank DRGs by the typical Resource Intensity Weight Value as recorded by the Centers for Medicare and Medicaid Services (CMS). This measure is used to proxy for the cost or reliance on specialized, expensive equipment. Higher resource intensity indicates a higher rank.

4) Rank DRGs by the percentage of procedures of this type performed in a teaching hospital. This measures the extent to which a diagnosis is performed at a university affiliated hospital, which are often centers for experimental, innovative and technically sophisticated services. A higher percentage corresponds to a higher rank.

We then sum these ranks across each DRG and calculate a rank based upon this number. Following the prescribed Hay Group (2001) cutoff points, we start with the highest ranked DRG we count the number of discharges with the highest rank which account for $10 \%$ of the discharges in the sample. These are classified as tertiary DRGs. The DRGs accounting for the next $40 \%$ of discharges are classified as secondary DRGs,

\footnotetext{
${ }^{5}$ For this measure, we use the county level Urban-Rural Classification Scheme developed by the National Center for Health Statistics.
} 
while the DRGs accounting for the lowest $50 \%$ are classified as primary. Table 1 contains information of the characteristics on individuals in each category. ${ }^{6}$

\section{Estimation}

Given the departure of our model from those previously estimated, our unique functional form necessitates a series of steps in order to produce an empirically tractable econometric model. This section details our estimation procedure and methods.

\subsection{Quantity Estimation}

As specified in equation (4), charges for hospital $j$ consist of components which vary by hospital-output type, output-specialty type and the quantity of care consumed by consumer $i$. Taking logs, equation (4) can be rewritten as:

$$
\log \left(H_{i j k n}\right)=\log \left(\gamma_{j k}\right)+\log \left(\frac{\partial C_{j}}{\partial Q_{k}}\right)+\log \left(\frac{\partial Q_{k}}{\partial Q_{k n}}\right)+\log \left(q_{i k}\right)
$$

which contains a hospital-specific markup factor, a term which varies by hospital-output type, an output-specialty specific term, and a measure of individual quantity consumed.

Our hospital charge data are not structured in a manner which allows for separate identification of the hospital-output specific or specialty-specific terms in equation (5). The construction of quantity for each hospital-output type, however, necessitates the identification of the quantity of output-type $k$ consumed by patient $i$. Our approach to identifying this term assumes the quantity of output type $k$ consumed by patient $i$ can be expressed as $q_{i k}=\exp \left(X_{i k} \beta_{k}\right)$, where $X_{i k}$ is a vector of patient demographic and

\footnotetext{
${ }^{6}$ Note that the cutoff thresholds for the types of care $(10 \% / 40 \% / 50 \%)$ are approximate, as the discharge data do not allow for exact cutoff thresholds. Due to the structure of the discharge data, the secondary and primary discharges are approximately $38 \%$ and $52 \%$ of the data, respectively.
} 
diagnostic characteristics. Given this assumption, identification of quantity in equation

(5) can be obtained by including a hospital-output type, specialty-specific term through a regression of the form:

$$
\log \left(H_{i j k n}\right)=\alpha_{j k n}+X_{i k} \beta_{k}+v_{i k n}
$$

where $\alpha_{j k n}$ is a hospital-output type specialty-specific term, $X_{i k}$ is a vector of observable patient characteristics and $\beta_{k}$ is a vector of coefficients to be estimated for these patient characteristics. Taking exponents, an estimator of the quantity of care type $K$ that person $i$ consumes, based on person $i$ 's observable characteristics can be written as:

$$
\hat{q}_{i k}=D * \exp \left(X_{i k} \hat{\beta}_{k}\right)
$$

where $D$ is Duan's (1983) smearing estimator.

Our delineation of medical specialty that follows classifies specialties according to the major diagnostic category (MDC) under which each patient's primary diagnosis is grouped. ${ }^{7}$ We estimate (6) separately for the three separate types of inpatient output (primary, secondary, tertiary), since our measure of quantity is assumed to meet the theoretically necessary conditions for aggregation only within an output-type. ${ }^{8}$ Given our assumption of charges varying by both hospital and specialty-specific factors, our outputspecific quantity regression contains fixed effects for each hospital-specialty combination. ${ }^{9}$ Included in our vector of patient and diagnostic characteristics are the type

\footnotetext{
${ }^{7}$ MDCs are formed by dividing all possible principal diagnoses into 25 mutually exclusive diagnosis areas, each of which corresponds to a single organ system or disease origin and are in general associated with a particular medical specialty. See.http://health.utah.gov/opha/IBIShelp/codes/MDC.htm

${ }^{8}$ Because our outpatient data contains only the total count of outpatient visits, we are unable to apply our framework to outpatient care. While our specification does include outpatient care, our measure of outpatient output is proxied using the number of outpatient visits.

${ }^{9}$ This necessitates the inclusion of $23 \times 321$ fixed effects for the tertiary quantity regression, $23 \times 321$ fixed effects for the secondary quantity regression and $18 \times 321$ fixed effects for the primary quantity regression.
} 
of admission, the number of procedures performed, MDC-level diagnosis categories, age, and gender. ${ }^{10}$

After estimating each of these three regressions, $\hat{q}_{i k}$ is recovered according to (7) for each patient. Using this functional form, each hospital's quantity of output $k$ specialty $n$ is calculated by summing over the entire universe of patients seeking care of a given output-specialty combination at that hospital, such that each hospital's quantity is calculated according to:

$$
Q_{j k n}=\sum_{i \rightarrow j} q_{i k n}
$$

where $i \rightarrow j$ denotes person $i$ consuming care at hospital $j .{ }^{11}$

\subsection{Cost Function Estimation}

As is common in previous studies of multiproduct firms, the basic structure of our estimated model incorporates the multiproduct transcendental logarithmic cost function (translog), one of the family of second-order Taylor-series approximations to an arbitrary cost function. The translog is particularly well suited to our application in that it imposes few a priori restrictions on the underlying nature of production, is sufficiently flexible to enable estimation of scope and scale economies, and is consistent with the functional properties required by economic theory. In addition, the translog functional form has been shown to provide a reasonable approximation for a production technology when no

\footnotetext{
${ }^{10}$ Because of the structure of the public-use California data, use of the full sample of available discharges necessitated the use of a categorical age variable available in the data, since the corresponding continuous age variable is masked for a substantial portion of the data.

${ }^{11}$ Estimation of the cost function specified in (10) is executed using a quantity of output type-specialty specific care that is normalized over all hospitals calculated and calculated as $\frac{Q_{j k n}}{\left[\frac{\left(\sum_{j=1}^{J} Q_{j k n}\right)}{J}\right]}$.
} 
explicit production or cost function is specified a priori (Guilkey, Lovell and Sickel, 1983; Stern, 1994).

Because of our inclusion of specialty-specific scope economies within an output type, we integrate into our system of estimating equations specialty-specific scope parameters as coefficients to be estimated. Specifically, our assumption of scope economies within each output type implies that the translog cost function with $K$ outputs and $M$ inputs, commonly represented as:

$$
\begin{aligned}
\log C(Q, w) & =\alpha_{o}+\sum_{r=1}^{K} \alpha_{r} \log Q_{r}+\sum_{s=1}^{M} \beta_{s} \log w_{s}+\frac{1}{2} \sum_{r=1}^{K} \sum_{t=1}^{K} \delta_{r t} \log Q_{r} \log Q_{t} \\
& +\frac{1}{2} \sum_{s=1}^{M} \sum_{v=1}^{M} \gamma_{s v} \log w_{s} \log w_{v}+\sum_{r=1}^{K} \sum_{s=1}^{M} \sigma_{r s} \log Q_{r} \log w_{s}+\epsilon
\end{aligned}
$$

can be written using the following estimation equation by substituting (2) into (9),

$$
\begin{aligned}
\log C(Q, w)=\alpha_{o} & +\sum_{r=1}^{K} \alpha_{r} \log \left(Q_{r 1}^{\rho_{r}}+\cdots+Q_{r N}^{\rho_{r}}\right)^{\frac{1}{\rho_{r}}}+\sum_{s=1}^{M} \beta_{s} \log w_{s} \\
& +\frac{1}{2} \sum_{r=1}^{K} \sum_{s=1}^{K} \delta_{r s} \log \left(Q_{r 1}^{\rho_{r}}+\cdots+Q_{r N}^{\rho_{r}}\right)^{\frac{1}{\rho_{r}}} \log \left(Q_{s 1}^{\rho_{s}}+\cdots+Q_{s N}^{\rho_{s}}\right)^{\frac{1}{\rho_{s}}} \\
& +\frac{1}{2} \sum_{s=1}^{M} \sum_{v=1}^{M} \gamma_{s v} \log w_{s} \log w_{v}+\sum_{r=1}^{K} \sum_{s=1}^{M} \sigma_{r s} \log \left(Q_{r 1}^{\rho_{r}}+\cdots+Q_{r N}^{\rho_{r}}\right)^{\frac{1}{\rho_{r}}} \log w_{s}+\epsilon
\end{aligned}
$$

As required to ensure the homogeneity of degree one in input prices, we impose the restrictions:

$$
\sum_{r=1}^{K} \alpha_{r}=1, \sum_{s=1}^{M} \gamma_{s v}=\sum_{v=1}^{M} \gamma_{s v}=\sum_{s=1}^{M} \sigma_{r s}
$$


While estimation of the translog could be done directly, gains in efficiency can be realized by estimating optimal, cost-minimizing input demand equations which can be obtained by logarithmically differentiating the cost function with respect to each input price to yield (for $\mathrm{i}=1, \ldots .8$ inputs):

$$
\frac{\partial \log C}{\partial \log w_{s}}=\frac{w_{s}}{C} \times \frac{\partial C}{\partial w_{s}}=\frac{w_{s} X_{s}}{C}=\beta_{s}+\sum_{v=1}^{M} \gamma_{s v} \log w_{v}+\sum_{r=1}^{K} \sigma_{r s} \log \left(Q_{r 1}^{\rho_{r}}+\cdots+Q_{r N}^{\rho_{r}}\right)^{\frac{1}{\rho_{r}}}+\epsilon_{s}
$$

where the second equality follows from Sheppard's Lemma and $\varepsilon_{s}$ is a disturbance term for the $s^{\text {th }}$ input equation. Because cost shares sum to unity, only 7 input share equations are independent. Thus one input demand equation must be deleted from the system. We choose the category "supplies and equipment" which we cannot observe in our data.

Assuming the nine restricted equations characterized in (10)-(12) have disturbances that are normally distributed, we can estimate this system of equations using iterative non-linear seemingly unrelated regression. This procedure provides estimates that are asymptotically equivalent to the consistent, asymptotically normal, and asymptotically efficient maximum likelihood estimator (Gallant, 1987; McElroy, Burmeister \& Wall, 1985; McElroy \& Burmeister, 1988;, Burmeister \& McElroy, 1988).

A key feature of this method versus previous methods used to model hospital production involves our treatment of each of the $\rho_{k}$ parameters in (10). Specifically, we treat each $\rho_{k}$ as a parameter to be estimated, rather restricting each of these parameters to equal one. The conventional translog specification is thus nested within this specification and therefore the assumption embedded in previous estimates of hospital costs that all $\rho_{k}=1$ are testable hypotheses within our model. In our framework, estimates of $\rho_{k}>1$ indicate the presence of economies of scope, while values of $\rho_{k}<1$ corresponds to 
diseconomies of scope and values of $\rho_{k}=1$ imply no economies or diseconomies of scope.

\section{Results}

A description of the variables used in the quantity regression of equation (6) can be found in Table 1. A total of 316,573 discharges are classified as tertiary, 1,220,335 as secondary, and 1,701,851 as primary. Tertiary and secondary patients are more likely to be older, as $70 \%$ and $68 \%$ of tertiary and secondary discharges are for individuals over the age of 35 , as opposed to $49 \%$ for primary care. A higher percentage of primary patients are female, with $59 \%$ of patients within this category classified as such, versus $31 \%$ and $47 \%$ for tertiary and secondary care. Racial composition is similar for the primary and secondary sample, while for the tertiary care sample a higher proportion of patients are unknown than for the other two samples. Tertiary patients are diagnosed with more diseases on average, are less likely to be an unscheduled admission than are secondary and primary patients, and are also more likely to have multiple procedures performed during a hospital stay.

The results of the quantity regression in equation (6) are presented in Table 2. A total of 176 diagnosis related groups (DRGs) are classified as tertiary using our criteria, while 265 DRGs are considered secondary and 67 DRGs are classified as primary. The average individual tertiary quantity for an individual patient using the estimated coefficients from this regression is 5.14 , while the average secondary quantity is 3.50 , and the average primary quantity is 2.03 . Primary care quantity is considerably less variable than tertiary and secondary quantity, as evidenced by the relatively narrow 
standard deviation relative to its mean for primary care versus secondary and tertiary care.

Table 3 presents a summary of the hospital-level quantities for each of the 25 specialties, where the average quantity across all patients within each type of care (primary, secondary, tertiary) has been normalized to equal 1. For example, within the circulatory specialty (MDC 5), the average amount of tertiary care produced is 382 units, while for secondary care and primary care the average hospital produces 567 units and 874 units, respectively. Similarly, for neurological care (MDC 1), the average amount of tertiary, secondary, and primary care produced are 89,275 , and 149 , respectively. In the tertiary and secondary output categories, circulatory care constitutes the largest amount of care, while the largest amount of primary care is provided in the childbirth and pregnancy specialty.

Table 4 presents examples of specific diagnosis related groups (DRGs) classified as tertiary, secondary, and primary care within three common specialties: circulatory, neurological, and newborn. While the full list of diagnoses within each care type is available from the authors upon request, Table 4 demonstrates the face validity of our classification criteria that groups output according to the input intensity level required to produce those outputs. For example, for the newborn specialty, tertiary care includes extreme immaturity (DRG 386) and prematurity with major problems (DRG 387), while normal newborn (DRG 391), a relatively input undemanding diagnosis is the only diagnosis included in the primary care category for this specialty.

A summary of hospital-level costs and wages paid to factor inputs is included in Table 5. The average annual cost of hospital production for our sample (using our 
calculated measure of capital expense) is $\$ 130,340$. For labor inputs, management is the highest paid factor of production, with an average hourly wage of $\$ 44.67$, while the lowest paid hospital workers are aides and orderlies, with an average hourly wage of \$21.80. Registered nurses (RNs), typically the largest expense for an inpatient hospital, are the highest paid healthcare workers, with an average hourly wage of $\$ 42.48$, while lower skilled licensed vocational nurses, nurses who typically work under the supervision of a physician or $\mathrm{RN}$ earn an average of $\$ 28.61$ per hour. The price of capital per bed using the measure outlined in section 4.3 is nearly $\$ 67,000$.

Table 6 reports our hospital-level regression results using the sample of 321 hospitals. With the exception of primary care, the first order coefficients for each type of care are insignificant at conventional levels. ${ }^{12}$ The within-output scope coefficients for tertiary and secondary care are less than 1 , indicating that diversification across specialties within these types of care is cost increasing. For primary care, however, the within-output coefficient is greater than 1 , indicating that diversification across specialties decreases costs. In section 7.2, we perform calculations to show how these specialty diversification parameter estimates affect cost calculations within an output type.

The own price elasticities with respect to each of these inputs are presented in Table 7. All point estimates of these elasticities are negative, as would be expected. Registered nurses (RNs) are the factor input with the lowest own-price elasticity (in absolute value) indicting that the production function is somewhat rigid with respect to

\footnotetext{
${ }^{12}$ The functional form used precludes normalization of the outputs in the cost function to the mean vector, as is done in many studies of this type. Consequently, the first order output coefficients cannot be interpreted as cost elasticities at the mean hospital, nor can the first order coefficients on the input coefficients be interpreted as shares.
} 
RN inputs. Though still inelastic, demand for Licensed Vocational Nurses (LVNs) appears to be more discretionary than for RNs with an own-price elasticity of -0.51 . The demand for medical supplies and equipment (-0.33), clerical staff (-0.47), aides and orderlies (-0.70) and technical and specialist labor (-0.84) are inelastic as well. However, as with Vita (1990), we find that management is the most price elastic input, with a price elasticity of -1.08 .

Table 8 presents calculations of the marginal cost of an average discharge for each of the 64 specialty-output combinations in our data. ${ }^{13}$ Our functional form necessitates a stylized construction of marginal costs. We calculate the marginal costs for each of the 64 outputs by calculating the incremental cost of producing an additional discharge of a given specialty-output type, holding all other specialty-output types constant at their respective sample means. For example, the average quantity weight for a tertiary nervous system discharge is 0.86 (not shown) while the mean quantity of tertiary care provided for nervous system diagnoses is 89.0 (from Table 3 ). Thus the marginal cost for a nervous system discharge is the change in cost of producing 89.86 units of tertiary care versus 89.0 units, holding constant each of the other 63 specialty-output combinations at their respective sample averages. Thus, holding all specialty-output combinations at the mean quantities that are detailed in Table 3, the marginal cost of an additional tertiary-nervous system discharge is $\$ 29,156$, while the marginal cost of an additional secondary-nervous system discharge is $\$ 8,056$ and the marginal cost of a primary-nervous system discharge is $\$ 133$.

\footnotetext{
${ }^{13}$ For 2 tertiary, 2 secondary and 7 primary specialties, there are no discharges, hence the 64 specialties rather than the full $25 \times 3=75$ specialties.
} 
Of note in this table are the substantial differences in marginal costs both within specialties, and across output categories. With the exception of MDC 17, Myeloproliferative DD (also known as a cancer of unknown primary site), within a given specialty the marginal cost of tertiary care is greater than that of secondary care, which is in turn greater than that of primary care. There also exists substantial variation in marginal costs within output types of output across specialties. For example, the marginal cost of treating a tertiary infectious disease case at the mean is nearly $\$ 169,000$, while the marginal cost of treating a primary care case of the same specialty is substantially less, at $\$ 251 .{ }^{14}$ Of particular note is the high marginal cost of providing tertiary care for HIV (MDC 25) and mental illnesses (MDC 19) at the average hospital in our data. Given the properties of our estimated cost function, these high marginal costs are likely due to the small number of cases of these output-specialty combinations present in our sample at the mean hospital.

In the analysis section that follows directly, we utilize the parameters of the cost function to investigate the properties of the cost surface. Significant departure of our cost function from actual costs along specific portions of the cost surface may invalidate any possible useful inference one could make using these estimates. Furthermore, as Vita (1990) notes, parametric cost functions can perform poorly at points distant from the means of the data. Table 9 presents predicted costs versus actual costs for six groups of hospitals based on the number of staffed beds at each hospital. Our estimated function appears to overestimate actual costs in hospitals with less than 145 beds and

\footnotetext{
${ }^{14}$ Specific examples of tertiary infectious disease diagnoses include operating room procedures for infectious \& parasitic diseases, postoperative \& post-traumatic infections, and other infectious \& parasitic diseases diagnoses. Examples of primary infectious disease diagnoses include septicemia and viral illnesses for individuals older than 17.
} 
underestimate actual costs in hospitals larger than this size. The extent of this overestimation worsens as the hospital size increases, and in the largest category (305875 beds) the function underestimates cost by nearly $13 \%$. Overall, however, the fit of our estimated function across these six size categories does not depart from actual costs by more than $13 \%$.

\section{Scope Economies and Scale Economies}

In the section that follows, we report results on the extent of scope and scale economies that are present using our output index and modified functional form. We report results for both within-output and across-output scope economies, as well as the degree of scale economies present using our method. Finally, we investigate the extent to which estimates of scale economies differ when using our method versus methods that have been used in previous studies of hospital costs.

\subsection{Scope Economies}

Our unique functional form enables calculation of two types of scope economies: within-output scope economies that exist between specialties within an output type, and across-output scope economies which exist across each type of output. Within-output scope economies are defined by the estimated $\rho_{t}, \rho_{s}$ and $\rho_{p}$ parameters corresponding to tertiary, secondary, and primary care, respectively, while across-output scope economies are defined using the definition of weak cost complementarities given by Baumol, Panzar and Willig (1982). The weak cost complementarities test defines a sufficient condition for the presence of scope economies between product $\mathrm{i}$ and product $\mathrm{j}$, as: 


$$
\frac{\partial^{2} C(Y)}{\partial Y_{i} \partial Y_{j}} \leq 0 .^{15}
$$

As indicated by the values of the estimated $\rho_{t}$, and $\rho_{s}$ parameters displayed in Table 6, substantial within-output diseconomies of scope are present for tertiary and secondary care, and these diseconomies of scope are statistically significant at conventional levels. These values imply that the joint production of specialties within tertiary and secondary care increases cost. For primary care we find statistically significant evidence of within-output economies of scope, implying that joint production of specialties within primary care is cost decreasing.

Table 10 presents examples of the costs savings and dis-savings due to specialization within an output category. Our calculation is done by first calculating a specialization index for each hospital-output type in the data. Within each output type, this specialization index is defined as a Herfindahl index, where a value of 1 indicates pure specialization. Using the calculated values of this specialization index, we compute costs for a hospital producing an equal quantity of each specialty within an output type that corresponds to a specialization level observed at points within the sample range. For example, the value of our specialization index for primary care at the $10^{\text {th }}$ percentile of specialization is 0.1283 , or equivalent to a hospital producing approximately 8 equally sized primary specialties. Thus the entry in row 2 , column 1 of Table $10(138,321)$ is the

\footnotetext{
${ }^{15}$ Using the coefficients of the translog, because $\frac{\partial \ln C}{\partial \ln Y_{i}}=\left(\frac{\partial C}{\partial Y_{i}}\right)\left(\frac{Y_{i}}{C}\right)$ and thus $\left(\frac{\partial C}{\partial Y_{i}}\right)=\left(\frac{\partial \ln C}{\partial \ln Y_{i}}\right) \cdot\left(\frac{C}{Y_{i}}\right)$, taking the derivative of the second equation with respect to $Y_{j}$ yields $\frac{\partial^{2} C(Y)}{\partial Y_{j} \partial Y_{i}}=\frac{C}{Y_{i} Y_{j}}\left[\left(\frac{\partial \ln C}{\partial \ln Y_{j}} \frac{\partial \ln C}{\partial \ln Y_{i}}\right)+\frac{\partial^{2} \ln C}{\partial \ln Y_{j} \partial \ln Y_{i}}\right]$. The calculation of weak cost complementarities proceeds using the term $\left(\frac{\partial \ln C}{\partial \ln Y_{j}} \frac{\partial \ln C}{\partial \ln Y_{i}}\right)+\frac{\partial^{2} \ln C}{\partial \ln Y_{j} \partial \ln Y_{i}}$; a value less than zero indicates the presence of economies of scope while a value greater than zero indicates diseconomies of scope. See Gilsdorf (1994) for a more detailed exposition.
} 
cost associated with producing the mean quantity of primary care allocated equally over eight specialties, holding constant the amount of secondary and tertiary care produced at their respective output-specialty sample averages. Similarly, the value of our specialization index for primary care at the $50^{\text {th }}$ percentile is 0.1589 , or equivalent to a hospital producing approximately 6 equally sized primary specialties. Thus the entry in row 2 , column 2 of Table $10(138,819)$ corresponds to the cost associated with producing the mean quantity of primary care allocated equally over six specialties, again holding constant the amount of secondary and tertiary care produced at their respective outputspecialty sample averages.

As is predicted by the specialization coefficients, there exist economies of scope for primary care, with the dis-savings of producing at the $90^{\text {th }}$ percentile of specialization versus the $10^{\text {th }}$ equal to approximately $1.5 \%$. For secondary care, as a hospital becomes more specialized, we observe a predicted decrease in cost from the $10^{\text {th }}$ to the $90^{\text {th }}$ specialization percentile, with costs decreasing from $\$ 122.1$ million to $\$ 119.4$ million, or approximately $2.2 \%$. For tertiary care, specialization also decreases cost, producing a predicted decrease of $\$ 37$ million, or nearly $31 \%$ as the specialization index increases from the $10^{\text {th }}$ to the $90^{\text {th }}$ percentile.

We present in Table A1 estimates of across-output type scope economies using the weak cost complementarities measure. Only two of these expressions are negative, and neither is significantly different from zero. Thus, using the weak cost complementarities measure, our function provides little evidence of across-output scope 
economies. This finding is consistent with those of Vita (1990) who finds no statistically significant evidence of weak cost complementarities. ${ }^{16}$

\subsection{Scale Economies}

The degree of scale economies is calculated according to the measure defined by Baumol, Panzar and Willig (1982). In the multiproduct case, returns to scale are defined as:

$$
S_{N}(y)=\frac{C(y)}{\sum_{i=1}^{n} y_{i} \frac{\partial C(y)}{\partial y_{i}}}=\frac{1}{\sum_{i=1}^{n} \frac{\partial \ln C(y)}{\partial \ln \left(y_{i}\right)}}
$$

and we calculate this measure by differentiating (9) with respect to the logarithm of each output type $\left(Q_{r}\right)$, and taking the reciprocal of the summation of the corresponding cost elasticities. The scale measure is evaluated for each level of output, $Q_{r}$, for the mean vector of each output-specialty combination. Using this measure, a number greater than one corresponds to increasing returns to scale, while a number less than 1 indicates decreasing returns to scale. Table 11 presents scale economies at output levels corresponding to the mean output vector (row 1) as well as output vectors corresponding output levels 50\% and 100\% larger than the mean (rows 2 and 3). Equating these numbers to bed size, row 1 would correspond to a hospital with approximately 185 beds, row 2 corresponds to a hospital with approximately 260 beds, while row 3 corresponds to a 340-bed hospital. At the mean output level, the estimates indicate increasing returns to

\footnotetext{
${ }^{16}$ A number of other studies (Cowing and Holtmann, 1983; Grannemann et al., 1986; Schffham et al., 1996) present parameters that are informative regarding the potential for economies of scope, however, they do not test the statistical significance of these parameters in their studies.
} 
scale. The point estimate of 1.21 implies that a $1 \%$ increase in all specialty-output combinations of care for the average hospital would lead to a $0.83 \%$ increase in costs for this hospital. Furthermore, this measure of scale economies is significantly different from 1 (the constant returns to scale threshold) at the $5 \%$ level. The point estimate continues to indicate economies of scale at the second output vector although the hypothesis of constant and even slightly decreasing returns to scale cannot be rejected. The point estimate of scale economies at the third output vector continues to indicate increasing returns to scale, however, the hypotheses of both increasing and decreasing returns to scale cannot be rejected at this output vector, due to the imprecision of the estimated scale measure.

Given that our estimated cost function indicates the presence of substantial scale economies, we investigate the extent to which our estimates of returns to scale differ from those that would be implied by methods used in previous studies that do not adjust for patient heterogeneity or account for within-output scope economies. To do so, using our same data, we estimate separate cost functions for 3 specifications that are similar to those employed in previous studies of hospital costs. Specifically, we separately estimate 1) A specification that defines output using only an unadjusted inpatient discharge count and outpatient visit count, 2) A specification that uses only an unadjusted inpatient discharge count and outpatient visit count while appending a case mix variable linearly onto the specification, ${ }^{17}$ and 3) A specification that aggregates unadjusted inpatient discharges into our three categories of output (primary, secondary, tertiary) and an

\footnotetext{
${ }^{17}$ We were able to obtain case-mix indices for 305 of our 321 hospitals.
} 
outpatient visit count. All specifications are estimated jointly with the appropriate input share equations, using iterated seemingly unrelated regression. ${ }^{18}$

Figure 1 plots point estimates of scale economies using each output measure. ${ }^{19}$ Point estimates from the output index indicate that scale economies are not exhausted over the entire sample range. Even at the point of 800 beds, our scale measure shows evidence of economies of scale, with a 1.046 measure implying that a $1 \%$ increase in output at this point leads to a $0.96 \%$ increase in cost. However, as indicated in Table 11 , the standard errors on these estimates of scale are large; $95 \%$ confidence intervals around the point estimates for the output index cannot reject the hypothesis that scale economies are exhausted at an output level equivalent to 260 beds. ${ }^{20}$ Using our alternatively specified functions that do not adjust for patient heterogeneity and do not account for within-output scope economies, we find evidence of the exhaustion of scale economies at smaller levels than would be implied using our modified specification. Point estimates of scale economies using a specification estimated using only a discharge and output visit count show exhaustion of scale economies at approximately 170 beds, and for this same specification we cannot reject at the $5 \%$ level the exhaustion of scale economies at 160 beds. Using a specification estimated using only a discharge and output visit count, while also appending a case-mix control, point estimates show exhaustion of scale economies at approximately 200 beds, while we cannot reject at the 5\% level the hypothesis of decreasing returns to scale at a level larger than 180 beds. For our specification

\footnotetext{
${ }^{18}$ For all specifications (including our base specification using the output index) standard errors for scale economies are computed using 400 bootstrapped replications.

${ }^{19}$ Bed equivalents are computed for each measure by regressing the number of beds on the respective measures of output (e.g., discharges (1 category) and outpatient visits, discharges ( 3 categories) and outpatient visits, and specialty-output combinations (64 categories) and outpatient visits).

${ }^{20}$ Confidence intervals for all specifications are estimated using 400 bootstrapped replications. Due to space constraints, we report the lower bound of the confidence intervals in the text.
} 
aggregating inpatient discharges into three separate types of output (primary, secondary and tertiary), point estimates indicate that minimum efficient scale is reached at approximately 230 beds, though we cannot reject at the $5 \%$ level the exhaustion of scale economies at levels as low as 210 beds.

These estimates provide evidence that previous studies may underestimate the size at which a hospital achieves minimum efficient scale, due in part to the use of econometric specifications that do not allow for the estimation of within-output specialty specific scope economies. The imposition of such parameter restrictions when estimating the extent of economies of scale and scope may thus not properly account for all properties of production inherent in the hospital industry. The additional theoretical refinements embodied in our output index affect estimates of scale economies and should be considered when modeling production in differentiated product industries such as the hospital industry, where both across-output as well as within-output across-specialty scope economies are likely to affect production.

\section{Conclusion}

In this study, we contribute to the body of econometric research on the specification and estimation of hospital cost functions by developing an output index which accounts for hospital case heterogeneity while also maintaining a functional form flexible enough to allow for theoretically sound estimates of scale and scope economies, both within hospital output types across specialties, and across output types. We find evidence of within-output scope economies for primary care and within-output scope diseconomies for tertiary and secondary care. We also find evidence that economies of 
scale using our method are exhausted at levels that are higher than those implied using methods that make use of less refined measures of output. Our research emphasizes the need for careful consideration of the nature of production when addressing policy questions involving differentiated products industries, and suggests that more flexible models of production for such firms can provide greater insights into the potential efficiency gains from consolidation in such industries. 


\section{References}

Baumol, William, John Panzar, and Robert Willig, Contestable Markets and the Theory of Industrial Structure (New York: Harcourt Brace Jovanovich, 1982).

Berndt, Ernst, The Practice of Econometrics: Classic and Contemporary (Reading, MA: Addison-Wesley, 1991).

Breyer, Fredrich, "The Specification of a Hospital Cost Function: A Comment on the Recent Literature," Journal of Health Economics 6:2 (1987), 147-157.

Burmeister, Edwin, and Marjorie B. McElroy, "Joint Estimation of Factor Sensitivities and Risk Premia for the Arbitrage Pricing Theory," Journal of Finance 43 (1988), 721735 .

Butler, J. (1995). Hospital Cost Analysis. Dordrecht: Kluwer Academic Publishers.

Carey, Kathleen, "A Panel Data Design for Estimation of Hospital Cost Functions," Review of Economics and Statistics 79:3 (1997), 443-453.

Caves, Douglas W., Laurits R. Christensen, and Michael W. Tretheway, "Flexible Cost Functions for Multiproduct Firms," The Review of Economics and Statistics 62:3 (1980), 477-481.

Caves, Douglas W., Laurits R. Christensen, and Michael W. Tretheway, "Economies of Density versus Economies of Scale: Why Trunk and Local Service Airline Costs Differ," The RAND Journal of Economics 15:4 (1984), 471-489.

Cohn, Elchanan, Sherrie L.W. Rhine, and Maria C. Santos, "Institutions of Higher Education as Multi-Product Firms: Economies of Scale and Scope," The Review of Economics and Statistics 71:2 (1989), 284-290.

Conrad, Robert F., and Robert P. Strauss, "A Multiple-Output Multiple-Input Model of the Hospital Industry in North Carolina," Applied Economics 15:3 (1983), 341-352.

Cowing, Thomas G., and Alphonse G. Holtman, "Multiproduct Short-Run Hospital Cost Functions: Empirical Evidence and Policy Implications from Cross-Section Data," Southern Economic Journal 49:3 (1983), 637-653.

Dor, Avi, and Dean E. Farley, "Payment Source and the Cost of Hospital Care: Evidence From A Multiproduct Cost Function With Multiple Payers," Journal of Health Economics 15 (1996), 1-21.

Dobson, Allen, Joan DaVanzo, Julia Doherty, and Myra Tanamor, "A Study of Hospital Charge Setting Practices," study conducted by the Lewin Group for MedPAC, No. 05-4, (2005). 
Dranove, David, "Economies of Scale in Non-Revenue Producing Cost Centers: Implications for Hospital Mergers," Journal of Health Economics 17:1 (1998), 69-83.

Duan, Naihua, "Smearing Estimate: A Nonparametric Retransformation Method," Journal of the American Statistical Association 78:383 (1983), 605-610.

Folland, Sherman, Allen C. Goodman, and Miron Stano, M., The Economics of Health and Health Care (New Jersey: Prentice-Hall, 2004).

Fournier, Gary M., and Jean M. Mitchell, "Hospital Costs and Competition for Services: A Multiproduct Analysis," The Review of Economics and Statistics 74:4 (1992), 627-634.

Gallant, A. Ronald, Nonlinear Statistical Models (New York: Wiley, 1987).

Garcia, Serge, and Alban Thomas, "The Structure Of Municipal Water Supply Costs: Application To A Panel Of French Local Communities," Journal of Productivity Analysis 16 (2001), 5-29.

Gaynor, Martin, and Gerard F. Anderson, "Hospital Costs and the Cost of Empty Hospital Beds," Journal of Health Economics 14:3 (1995), 291-317.

Gaynor, Martin, and William B. Vogt, "Antitrust and Competition in Health Care Markets," (Ch. 27) in Anthony J. Culyer and Joseph P. Newhouse (Eds.), Handbook of Health Economics, Vol. $1 B$ (New York: North-Holland, 2000).

Gilsdorf, Keith, "Vertical Integration Efficiencies and Electric Utilities: A Cost Complementarity Perspective," The Quarterly Review of Economics and Finance 34:3 (1994), 261-282.

Grannemann, Thomas W., Randall S. Brown, and Mark Pauly, "Estimating Hospital Costs: A Multiple Output Analysis," Journal of Health Economics 5:2 (1986), 107-127.

Guilkey, David K., Lovell, C.A.Knox., Sickles, Robin C., "A Comparison of the Performance of Three Flexible Functional Forms." International Economic Review 24:3 (1983) 591-616.

Gyimah-Brempong, Kwabena, "Economies of Scale in Municipal Police Departments: The Case of Florida," The Review of Economics and Statistics 69:2 (1987), 352-356.

Hall, Robert E., "The Specification of Technology with Several Kinds of Output," Journal of Political Economy 81:4 (1973), 878-892.

The Hay Group, “Level of Care Methodology: CMG 1999,” Reference Document \# RD 10-1. October (2001). Available at: 
http://www.ontla.on.ca/library/repository/mon/7000/10316275.pdf [Accessed March 27, 2012]

Keeler, Theodore E., and John S. Ying, "Hospital Costs and Excess Bed Capacity: A Statistical Analysis," Review of Economics and Statistics 78:3 (1996), 470-481.

Kim, H. Youn, "Economies of Scale in Multi-product Firms: An Empirical Analysis," Economica 54 (1987), 185-206.

McElroy, Marjorie B., Edwin Burmeister, and Kent D. Wall, "Two Estimators for the APT Model When Factors Are Measured,” Economics Letters 19 (1985), 271-275.

McElroy, Marjorie B., and Edwin Burmeister, "Arbitrage Pricing Theory as a Restricted Nonlinear Multivariate Regression Model: Iterated Nonlinear Seemingly Unrelated Regression Estimates," Journal of Business and Economics Statistics 6 (1988), 29-42.

Meade, Charles, and Jonathan Kulick, SB1953 and the Challenge of Hospital Seismic Safety in California. Prepared for the California Healthcare Foundation (2007) [Online] California HealthCare Foundation. Available at:

http://www.recoveryplatform.org/assets/submissions/200909020323_hospital_safety_in_ california.pdf [Accessed 27 March 2012].

McFadden, Daniel, "Cost, Revenue, and Profit Functions," (Ch. 1) in Melvyn Fuss and Daniel McFadden (Eds.), Production Economics: A Dual Approach to Theory and Applications, Volume 1 (Amsterdam: North Holland, 1978).

Mergent, Inc., Mergent Bond Record 74: 1 (New York: Mergent, 2007)

Moschini, GianCarlo, "A Model of Production with Supply Management for the Canadian Agricultural Sector," American Journal of Agricultural Economics 70 (1988), 318-329.

Nelson, Randy A., "Returns to Scale From Variable and Total Cost Functions, Evidence From the Electric Power Industry," Economic Letters 18:2-3 (1985), 271-276.

Office of Statewide Health Planning \& Development, "California's Seismic Safety Law: Its History, Implementation, \& Progress," (2005), p. 18.

Preyra, Colin, and George Pink, "Scale and Scope Efficiencies Through Hospital Consolidations," Journal of Health Economics 25:6 (2006), 1049-1068.

Pulley, Lawrence B., and Yale M. Braunstein, "A Composite Cost Function for Multiproduct Firms with an Application to Economies of Scope in Banking," Review of Economics and Statistics 74 (1992), 221-230. 
Röller, Lars-Hendrik, "Proper Quadratic Cost Functions with an Application to the Bell System," Review of Economics and Statistics 72 (1990), 202-210.

Romley, John A., and Goldman, Dana P., "How Costly Is Hospital Quality? A RevealedPreference Approach," The Journal of Industrial Economics 59:4 (2011), 578-608.

Stern, David. I., “Accuracy of the Translog Tunction," Applied Economics Letters, 1:10 (1994), 172-174.

Toft, Anders, and Trond Bjordal, "The Structure of Production in the Norwegian Fish Processing Industry: An Empirical Multi-Output Cost Analysis Using a Hybrid Translog Functional Form," Journal of Productivity Analysis 8 (1997), 247-267.

Vita, Michael G., "Exploring Hospital Production Relationships with Flexible Functional Forms," Journal of Health Economics 9:1 (1990), 1-21.

Wynn, Barbara O., "Inflation in Hospital Charges: Implications for the CA Workers' Compensation Program," testimony before California State Senate Labor and Industrial Relations Committee, January 15 (2003). 
Table 1: Descriptive Statistics: Individuals

\begin{tabular}{rrccc}
\hline Variable $r$ Full Sample & $\begin{array}{c}\text { Tertiary } \\
\text { Sample }\end{array}$ & $\begin{array}{c}\text { Secondary } \\
\text { Sample }\end{array}$ & $\begin{array}{c}\text { Primary } \\
\text { Sample }\end{array}$ \\
\hline Total Discharges & $3,238,759$ & 316,573 & $1,220,335$ & $1,701,851$ \\
Age & & & & \\
Under 1 Year & $14.8 \%$ & $5.2 \%$ & $10.0 \%$ & $20.1 \%$ \\
$1-17$ Years & $3.3 \%$ & $6.1 \%$ & $5.3 \%$ & $1.4 \%$ \\
$18-34$ Years & $17.9 \%$ & $7.4 \%$ & $10.6 \%$ & $25.1 \%$ \\
$35-64$ Years & $28.2 \%$ & $38.6 \%$ & $32.7 \%$ & $23.0 \%$ \\
$65+$ & $29.7 \%$ & $31.0 \%$ & $35.2 \%$ & $25.5 \%$ \\
Unknown & $6.0 \%$ & $11.6 \%$ & $6.2 \%$ & $4.9 \%$ \\
Sex & & & & \\
Male & $32.5 \%$ & $40.0 \%$ & $35.6 \%$ & $28.9 \%$ \\
Female & $51.2 \%$ & $30.6 \%$ & $46.6 \%$ & $58.3 \%$ \\
Race & $16.3 \%$ & $29.4 \%$ & $17.8 \%$ & $12.8 \%$ \\
White & $58.3 \%$ & & & \\
Black & $5.0 \%$ & $51.3 \%$ & $58.4 \%$ & $59.5 \%$ \\
Other/Unknown & $3.4 \%$ & $5.2 \%$ & $5.1 \%$ \\
Type of Admission & $36.7 \%$ & $45.2 \%$ & $36.4 \%$ & $35.4 \%$ \\
Scheduled & $21.2 \%$ & & & \\
Unscheduled & $64.5 \%$ & $47.8 \%$ & $27.4 \%$ & $11.8 \%$ \\
Infant & $14.1 \%$ & $48.5 \%$ & $64.8 \%$ & $67.3 \%$ \\
Unknown & $0.2 \%$ & $3.6 \%$ & $7.6 \%$ & $20.7 \%$ \\
& & $0.1 \%$ & $0.2 \%$ & $0.1 \%$ \\
Mean Number of Other Diagnoses & 4.4 & & & 3.7 \\
Mumber of Other Procedures & 0.9 & 5.4 & 5.1 & 0.5 \\
& & 2.9 & 1.0 & \\
\hline
\end{tabular}


Table 2: Quantity Regressions

\begin{tabular}{lcccccccc}
\hline Regression & Number of DRGs & $\begin{array}{c}\text { Number of } \\
\text { Discharges }\end{array}$ & $\begin{array}{c}\text { Number of } \\
\text { RHS } \\
\text { variables }\end{array}$ & $\mathbf{R}^{2}$ & $\begin{array}{c}\text { Average } \\
\text { quantity }\end{array}$ & Std. Dev. & Min & Max \\
\hline Primary & 67 & $1,701,851$ & 70 & 0.75 & 2.03 & 1.20 & 0.74 & 63.91 \\
Secondary & 265 & $1,220,335$ & 70 & 0.62 & 3.50 & 3.57 & 0.51 & 92.76 \\
Tertiary & 176 & 316,573 & 70 & 0.66 & 5.14 & 5.60 & 0.89 & 74.13 \\
\hline Table 2 reports results from regression equation (6) included in Section 5.1.
\end{tabular}

Table 2 reports results from regression equation (6) included in Section 5.1. 
Table 3: Average Hospital Quantity by MDC

\begin{tabular}{|c|c|c|c|c|c|c|}
\hline \multirow[b]{2}{*}{ Variable } & \multicolumn{2}{|c|}{ Tertiary Care } & \multicolumn{2}{|c|}{ Secondary Care } & \multicolumn{2}{|c|}{ Primary Care } \\
\hline & $\begin{array}{c}\text { Sample } \\
\text { Mean }\end{array}$ & $\begin{array}{l}\text { Standard } \\
\text { Deviation }\end{array}$ & $\begin{array}{c}\text { Sample } \\
\text { Mean }\end{array}$ & $\begin{array}{l}\text { Standard } \\
\text { Deviation }\end{array}$ & $\begin{array}{c}\text { Sample } \\
\text { Mean }\end{array}$ & $\begin{array}{l}\text { Standard } \\
\text { Deviation }\end{array}$ \\
\hline MDC 1 ( Nervous System) & 89.0 & 189.6 & 274.8 & 279.3 & 148.7 & 116.9 \\
\hline MDC 2 (Eye) & 4.3 & 12.7 & 5.9 & 10.4 & 0.0 & - \\
\hline MDC 3 (Ear, Nose, Mouth And Throat) & 24.4 & 57.2 & 28.8 & 35.4 & 20.5 & 19.5 \\
\hline MDC 4 (Respiratory System) & 50.5 & 68.8 & 438.6 & 374.1 & 540.2 & 371.6 \\
\hline MDC 5 (Circulatory System) & 382.3 & 652.1 & 566.5 & 614.0 & 873.8 & 696.6 \\
\hline MDC 6 (Digestive System) & 15.7 & 23.7 & 423.1 & 402.8 & 528.9 & 406.0 \\
\hline MDC 7 (Hepatobiliary System And Pancreas) & 27.9 & 72.7 & 301.3 & 275.5 & 0.0 & - \\
\hline MDC 8 (Musculoskeletal System And Connective Tissue) & 124.7 & 181.4 & 429.2 & 443.1 & 135.5 & 134.6 \\
\hline MDC 9 (Skin, Subcutaneous Tissue And Breast) & 8.3 & 19.5 & 167.6 & 180.8 & 33.9 & 39.8 \\
\hline MDC 10 (Endocrine, Nutritional And Metabolic System) & 40.8 & 108.0 & 66.6 & 67.1 & 223.9 & 160.1 \\
\hline MDC 11 (Kidney And Urinary Tract) & 32.8 & 74.2 & 183.9 & 177.2 & 169.2 & 131.6 \\
\hline MDC 12 (Male Reproductive System) & 8.8 & 13.7 & 27.9 & 28.2 & 11.5 & 13.7 \\
\hline MDC 13 (Female Reproductive System) & 17.5 & 31.5 & 211.2 & 231.4 & 0.0 & - \\
\hline MDC 14 (Pregnancy, Childbirth And Puerperium) & 0.0 & - & 128.6 & 153.3 & $1,472.8$ & $1,576.4$ \\
\hline MDC 15 (Newborn And Other Neonates) & 31.6 & 70.2 & 76.4 & 105.6 & 436.1 & 465.8 \\
\hline MDC 16 (Blood and Blood Forming Organs and Immunological Disorders) & 11.7 & 21.3 & 15.0 & 16.4 & 69.0 & 65.1 \\
\hline MDC 17 (Myeloproliferative DDs) & 39.2 & 91.3 & 33.0 & 48.3 & 0.0 & - \\
\hline MDC 18 (Infectious and Parasitic DDs) & 6.6 & 10.6 & 99.4 & 105.9 & 182.3 & 156.5 \\
\hline MDC 19 (Mental Diseases and Disorders) & 1.1 & 3.4 & 23.6 & 53.7 & 307.0 & 598.4 \\
\hline MDC 20 (Alcohol/Drug Use or Induced Mental Disorders) & 0.0 & - & 3.2 & 21.5 & 68.2 & 121.5 \\
\hline MDC 21 (Injuries, Poison And Toxic Effect of Drugs) & 19.4 & 28.6 & 42.8 & 57.8 & 66.3 & 58.3 \\
\hline MDC 22 (Burns) & 8.1 & 39.3 & 0.0 & - & 0.0 & - \\
\hline MDC 23 (Factors Influencing Health Status) & 7.1 & 16.4 & 227.1 & 398.4 & 13.9 & 15.8 \\
\hline MDC 24 (Multiple Significant Trauma) & 32.0 & 84.9 & 0.0 & - & 0.0 & - \\
\hline MDC 25 (Human Immunodeficiency Virus Infection) & 2.2 & 6.0 & 27.3 & 67.2 & 0.0 & - \\
\hline
\end{tabular}

Note: Hospital quantities are normalized so that the average quantity within an output type equals one. For example, within the circulatory specialty (MDC 5), the average

amount of tertiary care produced is 382 units, while for secondary care and primary care the average hospital produces 567 units and 874 units, respectively. 
Table 4: DRG Specific Examples of Care Types

Primary Care

\begin{tabular}{ccc}
\hline & Circulatory System & Newborns \\
\hline Nontraumatic stupor \& coma & Peripheral vascular disorders without & Normal newborn \\
Transient ischemia & complications & \\
& Hypertension \\
& Secondary Care & \\
\hline
\end{tabular}

\begin{tabular}{|c|c|c|}
\hline Nervous System & Circulatory System & Newborns \\
\hline Nervous system infection & $\begin{array}{l}\text { Peripheral vascular disorders with } \\
\text { complications }\end{array}$ & $\begin{array}{l}\text { Full-term neonate with major } \\
\text { problems }\end{array}$ \\
\hline $\begin{array}{l}\text { Nervous system tumors with } \\
\text { complications }\end{array}$ & Pacemaker replacement & $\begin{array}{c}\text { Premature delivery without major } \\
\text { problems }\end{array}$ \\
\hline & Tertiary Care & \\
\hline
\end{tabular}

\begin{tabular}{ccc} 
Nervous System & Circulatory System & Newborns \\
\hline Craniotomy (brain surgery) & Coronary bypass with cardiac catheter & Extreme immaturity or respiratory \\
Spinal disorders \& injuries & Major cardiovascular procedures with & distress syndrome \\
& complicating conditions & Prematurity with major problems
\end{tabular}

Note: A description of our classification criteria is included in Section 4.3. 
Table 5: Descriptive Statistics: Hospitals (N=321)

\begin{tabular}{|c|c|c|c|c|}
\hline Variable & $\begin{array}{c}\text { Sample } \\
\text { Mean }\end{array}$ & $\begin{array}{l}\text { Standard } \\
\text { Deviation }\end{array}$ & Min & Max \\
\hline Cost (in thousands) & 130,340 & 149,092 & 3,973 & $1,121,537$ \\
\hline \multicolumn{5}{|l|}{ Hourly Wages } \\
\hline Management $\left(\mathrm{w}_{1}\right)$ & 44.67 & 9.30 & 8.34 & 75.35 \\
\hline Technical and Specialist $\left(\mathrm{w}_{2}\right)$ & 33.57 & 7.23 & 8.39 & 54.17 \\
\hline Registered Nurse $\left(\mathrm{w}_{3}\right)$ & 42.48 & 8.72 & 17.29 & 70.29 \\
\hline Licenced Vocational Nurse $\left(\mathrm{w}_{4}\right)$ & 28.61 & 6.15 & 16.32 & 48.01 \\
\hline Aides and Orderlies $\left(\mathrm{w}_{5}\right)$ & 21.80 & 6.04 & 7.23 & 42.73 \\
\hline Clerical and Administrative $\left(\mathrm{w}_{6}\right)$ & 22.82 & 5.83 & 8.29 & 41.40 \\
\hline Capital Price (Per Bed) $\left(\mathrm{w}_{7}\right)$ & 66,979 & 32,089 & 15,955 & 217,482 \\
\hline
\end{tabular}


Table 6: Coefficient Estimates

\begin{tabular}{lcc}
\multicolumn{1}{c}{ Equation/Dependent Variable } & RMSE & $\mathbf{R}^{2}$ \\
\hline Total Cost & 0.228 & 0.990 \\
Management Share & 0.020 & 0.915 \\
Technical and Specialist Share & 0.026 & 0.948 \\
Registered Nurse Share & 0.036 & 0.952 \\
Licenced Vocational Nurse Share & 0.011 & 0.771 \\
Aides and Orderlies Share & 0.019 & 0.803 \\
Clerical Share & 0.020 & 0.934 \\
Capital Share & 0.032 & 0.924
\end{tabular}

Parameter Estimates

\begin{tabular}{|c|c|c|c|c|c|}
\hline $\begin{array}{r}\text { Parameter } \\
\text { Intercent }\end{array}$ & Estimate & Std. Error & Parameter & Estimate & Std. Error \\
\hline & & 2.83213 & & -0.01185 & 0.00769 \\
\hline Tertiary (TER) & -0.12132 & 0.35970 & $\mathrm{RN}^{*} \mathrm{AO}$ & 0.00229 & 0.01066 \\
\hline Secondary (SEC) & -0.17074 & 0.71949 & $\mathrm{RN}^{*} \mathrm{CL}$ & -0.01352 & 0.01042 \\
\hline Primary (PRIM) & $0.96116^{* * * *}$ & 0.28119 & RN*SUP & $-0.07834^{* * *}$ & 0.01149 \\
\hline Outpatient (OUT) & -0.32384 & 0.37956 & $\mathrm{RN} * \mathrm{CAP}$ & $-0.00738^{*}$ & 0.00439 \\
\hline rho tertiary & $0.44555^{* * *}$ & 0.03942 & LVN*AO & -0.00630 & 0.00664 \\
\hline rho secondary & $0.425688^{* * *}$ & 0.03450 & LVN*CL & -0.00879 & 0.00687 \\
\hline rho primary & $2.08001^{* *}$ & 0.83812 & LVN*SUP & $0.00765^{*}$ & 0.00405 \\
\hline $1 / 2 * \mathrm{TER}^{2}$ & $0.06912^{* *}$ & 0.02889 & LVN*CAP & $-0.00477^{* * *}$ & 0.00155 \\
\hline $1 / 2 * \mathrm{SEC}^{2}$ & $0.25098^{*}$ & 0.12927 & $\mathrm{AO} * \mathrm{CL}$ & -0.00350 & 0.00940 \\
\hline $1 / 2 *$ PRIM $^{2}$ & $0.16284^{* * *}$ & 0.03449 & AO*SUP & 0.00225 & 0.00658 \\
\hline $1 / 2 * \mathrm{OUT}^{2}$ & $0.12031^{* * *}$ & 0.03312 & $\mathrm{AO} * \mathrm{CAP}$ & $-0.01484^{* * * *}$ & 0.00254 \\
\hline TER*SEC & -0.07881 & 0.05808 & CL*SUP & $-0.02044^{* * *}$ & 0.00654 \\
\hline TER*PRIM & 0.03602 & 0.02261 & $\mathrm{CL} * \mathrm{CAP}$ & 0.00316 & 0.00249 \\
\hline TER*OUT & 0.03297 & 0.03054 & CAP*SUP & -0.00102 & 0.00770 \\
\hline SEC*PRIM & $-0.14626^{* *}$ & 0.06354 & MS*TER & $-0.00316^{*}$ & 0.00187 \\
\hline SEC*OUT & -0.05778 & 0.05426 & MS*SEC & 0.00143 & 0.00401 \\
\hline PRIM*OUT & $-0.06558^{* *}$ & 0.03323 & MS*PRIM & $-0.00585^{* * *}$ & 0.00204 \\
\hline Management Wage (MS) & $0.10564 * * *$ & 0.02354 & MS*OUT & 0.00098 & 0.00168 \\
\hline Technical and Specialist Wage (TS) & -0.00814 & 0.03161 & TS*TER & -0.00338 & 0.00246 \\
\hline Registered Nurse Wage (RN) & $0.29334 * * *$ & 0.04353 & TS*SEC & $0.01318^{* *}$ & 0.00530 \\
\hline Licenced Vocational Nurse Wage (LVN) & 0.00185 & 0.01395 & TS*PRIM & $-0.00460 *$ & 0.00270 \\
\hline Aides and Orderlies Wage (AO) & -0.00095 & 0.02324 & TS*OUT & 0.00293 & 0.00222 \\
\hline Clerical Wage (CL) & 0.03646 & 0.02343 & $\mathrm{RN} * \mathrm{TER}$ & $0.01658^{* * *}$ & 0.00338 \\
\hline Supplies/Equpment Price (SUP) & $0.34696^{* * *}$ & 0.08644 & RN*SEC & $-0.02170^{* * *}$ & 0.00733 \\
\hline Capital Price (CAP) & $0.22483^{* * *}$ & 0.03748 & RN*PRIM & $0.01731^{* * *}$ & 0.00382 \\
\hline $1 / 2 * \mathrm{MS}^{2}$ & -0.00928 & 0.00948 & RN*OUT & $-0.01379^{* * *}$ & 0.00303 \\
\hline $1 / 2 * \mathrm{TS}^{2}$ & 0.00559 & 0.01453 & LVN*TER & $-0.00685^{* * *}$ & 0.00109 \\
\hline $1 / 2 * \mathrm{RN}^{2}$ & $0.11888^{* * *}$ & 0.02043 & LVN*SEC & $0.00848^{* * *}$ & 0.00230 \\
\hline $1 / 2 * \mathrm{LVN}^{2}$ & 0.00883 & 0.00811 & LVN*PRIM & 0.00070 & 0.00117 \\
\hline $1 / 2 * \mathrm{AO}^{2}$ & 0.00988 & 0.01127 & LVN*OUT & $-0.00237^{* *}$ & 0.00098 \\
\hline $1 / 2 * \mathrm{CL}^{2}$ & $0.03386^{* * *}$ & 0.01240 & AO*TER & $-0.00779^{* * *}$ & 0.00181 \\
\hline $1 / 2 * \mathrm{SUP}^{2}$ & $0.10296^{* * *}$ & 0.02123 & $\mathrm{AO} * \mathrm{SEC}$ & $0.01124^{* * *}$ & 0.00388 \\
\hline $1 / 2 * \mathrm{CAP}^{2}$ & $0.03511^{* * *}$ & 0.00439 & AO*PRIM & $-0.00390^{* *}$ & 0.00198 \\
\hline MS*TS & 0.01145 & 0.00893 & AO*OUT & 0.00036 & 0.00165 \\
\hline MS*RN & -0.00565 & 0.01007 & CL*TER & -0.00294 & 0.00184 \\
\hline MS*LVN & 0.00042 & 0.00545 & CL*SEC & -0.00590 & 0.00395 \\
\hline MS*AO & $-0.01326^{*}$ & 0.00735 & CL*PRIM & 0.00223 & 0.00200 \\
\hline MS*CL & $0.01597^{* *}$ & 0.00769 & CL*OUT & $0.01018^{* * *}$ & 0.00167 \\
\hline MS*SUP & 0.00303 & 0.00660 & CAP*TER & $-0.01292^{* * *}$ & 0.00296 \\
\hline MS*CAP & -0.00268 & 0.00256 & $\mathrm{CAP} * \mathrm{SEC}$ & $0.01255^{*}$ & 0.00643 \\
\hline TS*RN & -0.00443 & 0.01199 & CAP*PRIM & 0.00137 & 0.00327 \\
\hline TS*LVN & $0.01481^{* *}$ & 0.00667 & CAP*OUT & $-0.01392^{* * *}$ & 0.00268 \\
\hline TS*AO & $0.02348^{* * *}$ & 0.00900 & SUP*TER & $0.02046^{* * *}$ & 0.00672 \\
\hline TS*CL & -0.00676 & 0.00956 & SUP*SEC & -0.01929 & 0.01468 \\
\hline TS*SUP & $-0.03654^{* * *}$ & 0.00854 & SUP*PRIM & -0.00726 & 0.00749 \\
\hline TS*CAP & $-0.00759^{* *}$ & 0.00322 & SUP*OUT & $0.01563 * *$ & 0.00614 \\
\hline
\end{tabular}

*** Denotes Significance at the $1 \%$ level

** Denotes Significance at the $5 \%$ level

* Denotes Significance at the $10 \%$ level 
Table 7:

Estimated Own-price elasticity for inputs

\begin{tabular}{ccc}
\hline Input Price & Share & Price Elasticity \\
\hline Management & 0.064 & -1.081 \\
Technical \& Specialist & 0.112 & -0.838 \\
RNs & 0.158 & -0.089 \\
LVNs & 0.019 & -0.514 \\
Aides and Orderlies & 0.037 & -0.698 \\
Clerical & 0.073 & -0.465 \\
Supplies and Equipment & 0.428 & -0.331 \\
Capital & 0.109 & -0.568
\end{tabular}

Calculated as $\left(\gamma_{\mathrm{ii}}+\mathrm{S}_{\mathrm{i}} \mathrm{S}_{\mathrm{j}}\right) / \mathrm{S}_{\mathrm{i}}$. See Berndt (1991). 
Table 8:

Marginal Cost of a Discharge at the Mean Hospital

\begin{tabular}{|c|c|c|c|}
\hline \multirow{2}{*}{ Specialty (MDC) } & \multicolumn{3}{|c|}{ Marginal Cost by Output Type } \\
\hline & Tertiary & Secondary & Primary \\
\hline MDC 1 ( Nervous System) & 29,156 & 8,046 & 133 \\
\hline MDC 2 (Eуe) & 101,816 & 54,291 & 0 \\
\hline MDC 3 (Ear, Nose, Mouth And Throat) & 44,541 & 19,978 & 14 \\
\hline MDC 4 (Respiratory System) & 65,821 & 7,591 & 520 \\
\hline MDC 5 (Circulatory System) & 19,995 & 8,372 & 874 \\
\hline MDC 6 (Digestive System) & 83,779 & 8,580 & 515 \\
\hline MDC 7 (Hepatobiliary System And Pancreas) & 100,585 & 8,530 & 0 \\
\hline MDC 8 (Musculoskeletal System And Connective Tissue) & 23,797 & 5,902 & 112 \\
\hline MDC 9 (Skin, Subcutaneous Tissue And Breast) & 89,610 & 10,173 & 20 \\
\hline MDC 10 (Endocrine, Nutritional And Metabolic System) & 37,265 & 14,358 & 212 \\
\hline MDC 11 (Kidney And Urinary Tract) & 49,364 & 13,084 & 150 \\
\hline MDC 12 (Male Reproductive System) & 63,522 & 31,223 & 6 \\
\hline MDC 13 (Female Reproductive System) & 81,181 & 9,864 & 0 \\
\hline MDC 14 (Pregnancy, Childbirth And Puerperium) & 0 & 11,318 & 1,315 \\
\hline MDC 15 (Newborn And Other Neonates) & 49,195 & 4,466 & 133 \\
\hline MDC 16 (Blood and Blood Forming Organs and Immunological Disorders) & 60,594 & 42,821 & 58 \\
\hline MDC 17 (Myeloproliferative DDs) & 35,187 & 40,565 & 0 \\
\hline MDC 18 (Infectious and Parasitic DDs) & 168,778 & 21,675 & 251 \\
\hline MDC 19 (Mental Diseases and Disorders) & 234,261 & 21,739 & 232 \\
\hline MDC 20 (Alcohol/Drug Use or Induced Mental Disorders) & 0 & 103,124 & 50 \\
\hline MDC 21 (Injuries, Poison And Toxic Effect of Drugs) & 76,470 & 19,211 & 55 \\
\hline MDC 22 (Burns) & 104,695 & 0 & 0 \\
\hline MDC 23 (Factors Influencing Health Status) & 110,182 & 11,598 & 11 \\
\hline MDC 24 (Multiple Significant Trauma) & 91,853 & 0 & 0 \\
\hline MDC 25 (Human Immunodeficiency Virus Infection) & 431,550 & 38,238 & 0 \\
\hline
\end{tabular}

The "mean hospital" corresponds to a hospital providing the average quantity of each type of care within each specialty-output Marginal costs for each of the 64 outputs calculated using the incremental cost of producing an additional discharge of a given specialty-output type, holding all other specialty-output types constant at their respective sample means. See section 6

for a detailed explantion. 
Table 9:

Function Fit

\begin{tabular}{lccc}
\hline \multicolumn{1}{c}{ Bed Size } & N & Mean Cost & $\begin{array}{c}\text { Mean } \\
\text { Predicted Costs }\end{array}$ \\
\hline 10-57 beds & 54 & 24,102 & 26,644 \\
58-100 beds & 53 & 46,558 & 47,961 \\
101-144 beds & 54 & 70,106 & 70,263 \\
$145-215$ beds & 53 & 114,651 & 112,241 \\
216-301 beds & 54 & 177,818 & 172,981 \\
305-876 beds & 53 & 351,049 & 305,047 \\
\hline All amounts in thousands of dollars. & &
\end{tabular}


Table 10:

Cost of Specialization

\begin{tabular}{|c|c|c|c|}
\hline & \multicolumn{3}{|c|}{ Specialization Percentile } \\
\hline & \multicolumn{3}{|c|}{ (more specialized) } \\
\hline & 10th percentile & 50th percentile & 90th percentile \\
\hline \multicolumn{4}{|l|}{\begin{tabular}{|l} 
Primary Care \\
\end{tabular}} \\
\hline Number of primary care specialties in specialization percentile & 8 specialties & 6 specialties & 4 specialties \\
\hline Cost of providing the mean primary care quantity by specialization percentile & 138,321 & 138,819 & 140,387 \\
\hline \multicolumn{4}{|l|}{ Secondary Care } \\
\hline Number of secondary care specialties in specialization percentile & 11 specialties & 10 specialties & 7 specialties \\
\hline Cost of providing the mean secondary care quantity by specialization percentile & 122,099 & 120,587 & 119,408 \\
\hline \multicolumn{4}{|l|}{$\begin{array}{c}\text { Tertiary Care } \\
\end{array}$} \\
\hline Number of tertiary care specialties in specialization percentile & 10 specialties & 5 specialties & 2 specialties \\
\hline Cost of providing the mean tertiary care quantity by specialization percentile & 118,562 & 97,525 & 81,517 \\
\hline
\end{tabular}

Table 10 entries computed as follows by first calculating a Herfindahl specialization index for each hospital-output type in the data (value of 1 indicates pure

specialization). Costs are displayed for a hospital producing an equal quantity of each specialty corresponding to a specialization level observed at points within the sample range. For example, the value of our specialization index for primary care at the 10th percentile of specialization is 0.1283 , or equivalent to a hospital

producing approximately 8 equally sized primary specialties. Thus the entry in row 2 , column 1 of $(138,321)$ is the cost associated with producing the mean quantity of primary care allocated equally over eight specialties, holding constant the amount of secondary and tertiary care produced at their respective output-specialty sample averages. See section 7.1 for a detailed explanation.

Note that the quantities of tertiary and secondary care are held constant at their sample averages for the primary care calculations, quantities of

tertiary and primary care are held constant at their sample averages for the secondary care calculations, and quantities of primary and secondary care are held constant at their sample averages for the tertiary care calculations. 
Table 11:

Scale Economies by Hospital Size

\begin{tabular}{|c|c|c|c|c|c|c|c|}
\hline Beds & Primary Discharges & Secondary Discharges & Tertiary Discharges & Outpatient Visits & Scale & $\begin{array}{r}95 \% \text { Con } \\
\text { Lower }\end{array}$ & $\begin{array}{l}\text { e Interval } \\
\text { Upper }\end{array}$ \\
\hline 185 & 5,302 & 3,802 & 986 & 122,030 & 1.21 & 1.11 & 1.44 \\
\hline 260 & 7,953 & 5,703 & 1,479 & 183,045 & 1.16 & 0.99 & 1.98 \\
\hline 340 & 10,603 & 7,603 & 1,972 & 244,060 & 1.13 & 0.88 & 2.53 \\
\hline
\end{tabular}

Row 1 corresponds to the mean output vector, while rows 2 and 3 respectively correspond to output vectors $50 \%$ and $100 \%$ larger than the mean. Std. Errors are bootstrapped using 400 replications 
Table A1:

Economies of Scope at Mean Output

\begin{tabular}{lccc}
\multicolumn{1}{c}{ Output Measures } & \multicolumn{2}{c}{ Scope } & \multicolumn{2}{c}{ 95\% Confidence Interval } \\
& (weak cost complementarities) & Lower & Upper \\
\hline Tertiary, Secondary & 0.02 & -0.18 & 0.23 \\
Tertiary, Primary & 0.03 & -0.12 & 0.15 \\
Tertiary, Outpatient & 0.09 & -0.01 & 0.20 \\
Secondary, Primary & -0.12 & -0.44 & 0.25 \\
Secondary, Outpatient & 0.00 & -0.22 & 0.19 \\
Primary, Outpatient & -0.05 & -0.18 & 0.06 \\
\end{tabular}

Note: Std. Errors are bootstrapped using 400 replications 


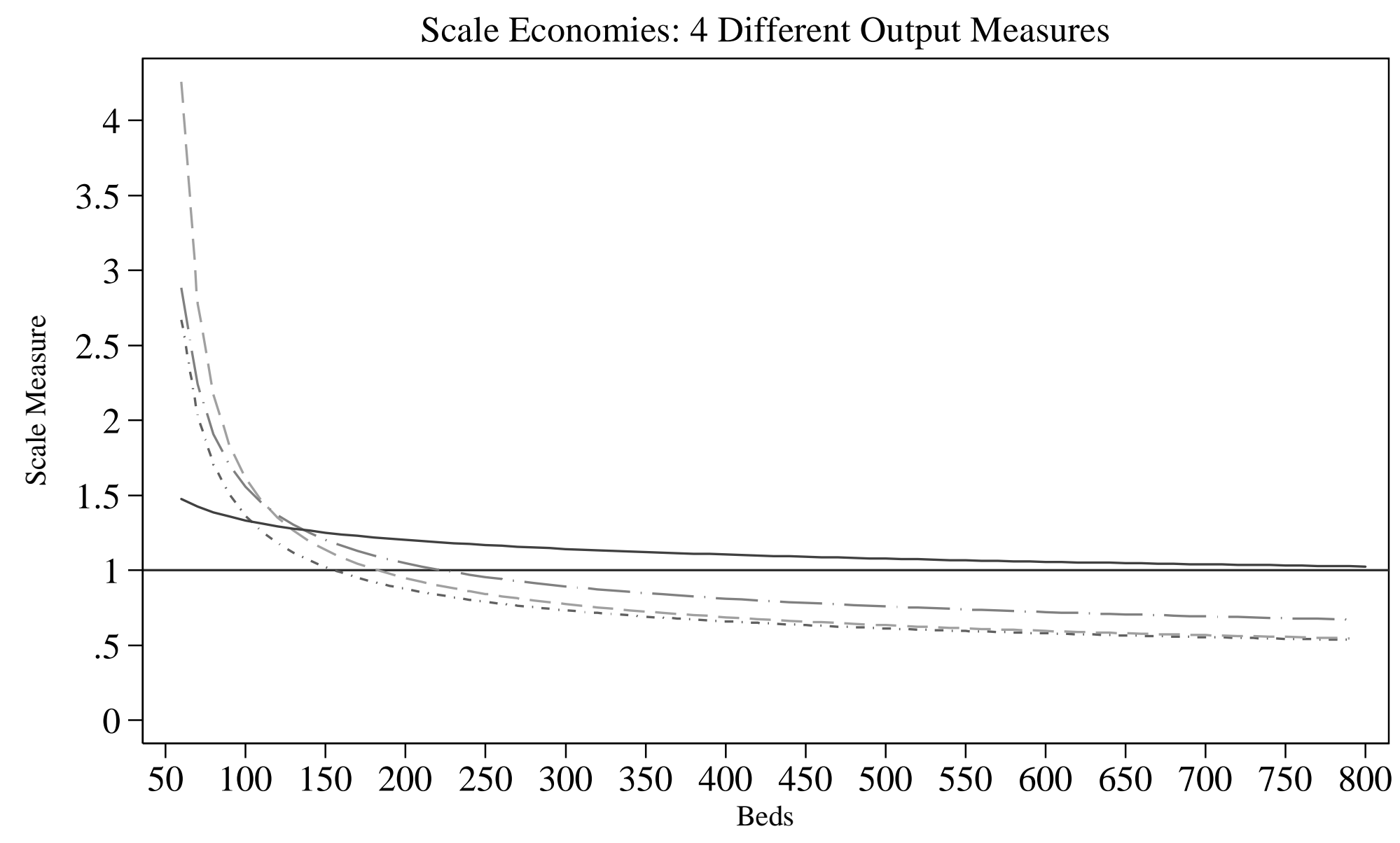

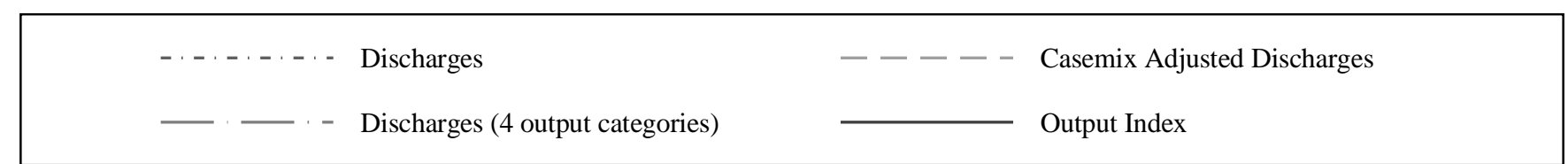

